\title{
Um novo gênero e três espécies novas de Membracidae (Homoptera) do Brasil. ${ }^{1}$
}

\author{
Antonio José Creão Duarte ${ }^{2}$ \\ Albino M. Sakakibara ${ }^{3}$
}

\begin{abstract}
A new genus and three new species of Membracidae (Homoptera) are described from Brazil: Ramedia gen. $n$. - R. juncta sp. n. (from Rio Branco-AC), R. costata $s p$. $n$. (from Sinop-MT) and $\mathbf{R}$. pauperata $s p$. $n$. (from Batatais-SP).
\end{abstract}

Espécie-tipo: Ramedia juncta sp. n.

Ramedia gen. $\mathbf{n}$.

Cabeça triangular, duas vezes mais larga que longa; vértice mais ou menos plano, de superfïcie fortemente pontuada, margem superior distintamente sinuosa; ocelos conspicuos situados logo abaixo da linha imaginária que passa pelo centro dos olhos, equidistantes entre si e dos olhos; clipeo pequeno quase tão largo quanto longo, em vista frontal mais ou menos no mesmo plano do vértice, ápice arredondado, em vista lateral truncado.

Pronoto tectiforme, mais elevado acima dos ângulos umerais e terminando junto ao ápice das tegminas, com os bordos laterais cobrindo mais ou menos $2 / 3$ das mesmas; de superfície grosseiramente pontuada e evidenciando 5-6 linhas elevadas longitudinais de cada lado, mais ou menos paralelas entre si; carena dorsal cortante, sub-foliácea.

Tegminas coriáceas na base e na porção exposta e, a parte que fica escondida pelo pronoto, hialina; veias bem distintas, com a $\mathbf{R}$ e $\mathbf{M}$ unidas na base por um curto trajeto e ramificando-se após o meio; $\mathrm{Cu}$ livre desde a base; cinco células apicais, a terceira menor, peciolada, com o ramo $\mathrm{R} 4+5$ bem menor que a M1 + 2, a quinta discoidal maior, em forma de um triângulo retângulo; transversas $r$ e duas m-cu's presentes. Asas hialinas, com quatro células apicais, a segunda peciolada.

Pernas normais, prismáticas, com basitarsos posteriores providos de pequenos dentes plantares.

${ }^{1}$ Contribuição n ${ }^{0}$. do Departamento de Zoologia-UFPR.

${ }^{2}$ Departamento de Ciências Agrárias, Universidade Federal do Acre. Cx. P. 425, 69900 Rio Branco - AC.

${ }^{3}$ Departamento de Zoologia, Universidade Federal do Paraná. Cx.P. 19020, 81540 - Curitiba-PR. Bolsista do CNPq. 
Genitália: Pigóforo com lobos laterais bem distintos, mais ou menos arredondados; edeago sub-cilíndrico, levemente curvo para cima e com dentículos látero-apicalmente; parâmeros normais, falciformes e terminados em ponta.

Comentário: Este gênero é muito próximo de Gelastogonia, Adippe e Hemipticha. Assemelha-se ao primeiro pela presença de linhas elevadas laterais no pronoto; ao segundo, pela forma geral e pontuação; a Hemipticha no que se refere à venação das tegminas com a $\mathbf{R}$ e $\mathbf{M}$ unidas na base por um curto trajeto. Difere de todos os gêneros acima citados pela presença de duas células discoidais em decorrência das transversas $r$ e duas $\mathrm{m}$-cu's.

\section{Ramedia juncta sp. n.}

(Figs.

Caracteres diagnósticos: Pronoto elevado acima dos ângulos umerais, de contorno superior largamente arqueado em direção ao ápice das tegminas; carena dorsal sub-foliácea e levemente projetada à frente do metopídio.

Medidas (em mm): Fêmea (holótipo)/Macho. Largura máxima da cabeça $2,44 / 2,26$; comprimento da cabeça $1,16 / 1,12$; largura entre os ângulos umerais 2,92/2,64; comprimento total 5,92/5,24.

Tipo e localidade-tipo: Holótipo fêmea de "Brasil-Acre/Rio Branco/07. VIII-1988/Creão Duarte leg.". Parátipos: 7 fêmeas e 4 machos com os mesmos dados do holótipo. 1 macho de "PN. Xingu-MT, Brasil XI-1961, M. Alvarenga leg." Os tipos acham se depositados no Museu de Entomologia Pe. Jesus S. Moure, do Departamento de Zoologia da UFPR.

Descrição: Holótipo fêmea. Coloração geral amarelo-palha com algo de alaranjado no fundo das pontuações. Cabeça, pronoto e base das tegminas grosseiramente pontuados, com pilosidade curta e ereta. Cabeça distintamente triangular, mais larga que longa; margem superior sinuosa; ocelos conspícuos situados logo abaixo da linha imaginária que passa pelo centro dos olhos, equidistantes entre si e dos olhos; estes pouco salientes e ovalados; clipeo em forma aproximada de um losango, levemente protuberante no meio, em vista lateral truncado apicalmente; lóbulos supra-antenais no mesmo plano do vértice, com os bordos levemente sinuosos.

Pronoto tectiforme, elevado verticalmente acima da cabeça e de contorno superior largamente arqueado até o ápice das tegminas, ficando o ponto mais elevado logo atrás dos ângulos umerais; carena média dorsal bem evidente e laminar desde a altura dos olhos onde se projeta levemente à frente, até a extremidade posterior; partes laterais, após os ângulos umerais, de superfïcies mais ou menos ondulada, providas de linhas longitudinais elevadas e lisas, em número de $5-6$.

Tegminas com aproximadamente $2 / 3$ encobertas pelo pronoto; a base e aproximadamente até o meio da porção exposta, coriácea e fortemente pontuada como o pronoto; porção encoberta, inteiramente hialina; venação bem distinta e saliente, com cinco células apicais e duas discoidais. Asas hialinas, venação escura, quatro células apicais.

Macho: Semelhante à fêmea, apenas um pouco menor. Genitália: pigóforo com lobos laterais mais ou menos arredondados; placa sub-genital bipartida; 
edeago sub-cilïndrico, levemente curvo para cima, 2,5 vezes mais longo que largo, levemente afilado para o ápice, com um pequeno dente dorso-apicalmente e outros diminutos lateralmente na altura do forâmen distal; parâmeros robustos, mais ou menos falciformes, terminados em ponta aguda.

\section{Ramedia costata sp. n.}

(Figs.

Caracteres diagnósticos: Pronoto baixo, de coloração amarelada e com manchas acastanhadas no metopidio; linhas elevadas laterais bem marcadas.

Medidas (em mm): Fêmea (holótipo)/Macho. Largura máxima da cabeça $1,66 / 1,76$; comprimento da cabeça $0,80 / 0,86$; largura entre os ângulos umerais $1,86 / 1,96$; Comprimento total 4,0/4,24.

Tipo e localidade-tipo: Holótipo fêmea de "Sinop-MT, Brasil/ S12 31 'W55 37'/X/1974 - M. Alvarenga leg.". Parátipo macho com os mesmos dados do holótipo. Os tipos acham se depositados no Museu de Entomologia Pe. Jesus S. Moure, do Departamento de Zoologia da UFPR.

Descrição: Holótipo fêmea. Coloração geral amarela, com três manchas acastanhadas mais ou menos alongadas e de contorno difuso, no metopídio desde a base da cabeça até a altura dos ângulos umerais.

Pronoto baixo, de contorno superior quase reto após os ângulos umerais. Outros caracteres semelhantes a $R$. juncta.

Macho: ligeiramente maior. Genitália: Pigóforo com os lobos laterais estreitados e terminados superiormente em uma pequena projeção rombuda; edeago sub-cilindrico, quase quatro vezes mais longo que largo, provido de um pequeno dente dorso apicalmente e uma fileira de dentículos de cada lado perto do ápice; parâmeros robustos, falciformes e pontiagudos.

Comentário: Esta espécie difere da anterior pelo seu tamanho reduzido e pelo pronoto que não é fortemente elevado nem projetado para frente, acima do metopídio; este com manchas acastanhadas difusas.

\section{Ramedia pauperata sp. n.}

(Figs.

Caracteres diagnósticos: Pronoto pouco elevado, com a carena média dorsal sub-foliácea após os ângulos umerais; concolorido.

Médias (em mm): Fêmea. Largura máxima da cabeça 2,48; comprimento da cabeça 1,12; largura entre os ângulos umerais 3,12; comprimento total 6,88 .

Tipo e localidade-tipo: Holótipo fêmea de "Batatais-SP/Brasil. 2/I/1968/ Pe. J. Moure leg.". Exemplar único e acha-se depositado no Museu de Entomologia Pe. Jesus S. Moure do Departamento de Zoologia da UFPR.

Descrição: Holótipo fêmea. Coloração geral amarelo-palha. Cabeça e pronoto fortemente pontuado, de aspecto quase corrugado. Pronoto moderadamente elevado, com carena média dorsal absoleta acima do metopídio e sub-foliácea depois dos ângulos umerais; linhas elevadas laterais fracas e confusas. Demais caracteres emelhantes aos das espécies anteriores. 
Comentário: Esta espécie é a maior, quase do dobro do tamanho de $R$. costata. O pronoto é moderadamente elevado, com o ponto mais alto localizado depois dos ângulos umerais; carena média dorsal fraca na frente, tornando se sub-foliácea para trás. A terceira célula apical das tegminas distintamente transversa, com o ramo R4+5 curtǐssimo, praticamente ausente.
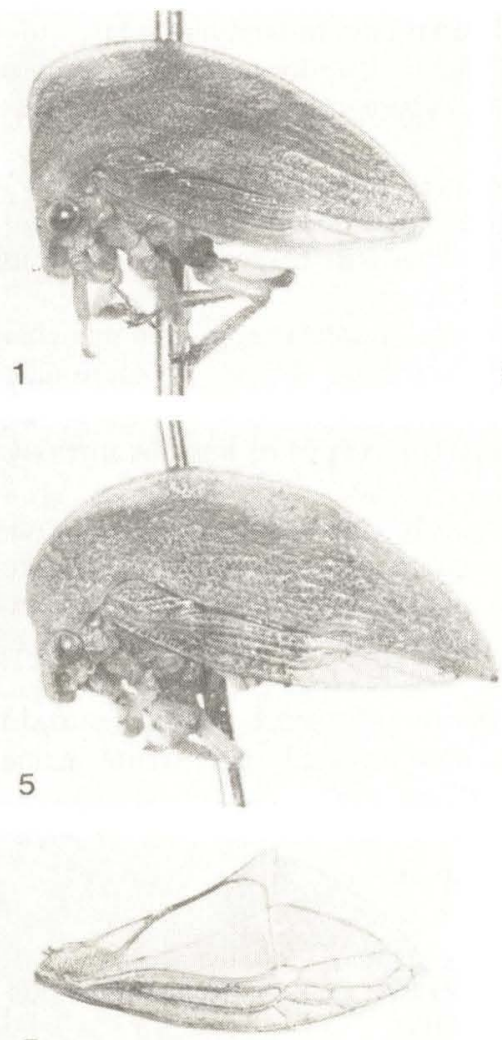

7

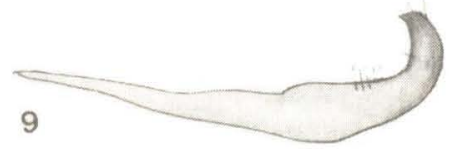

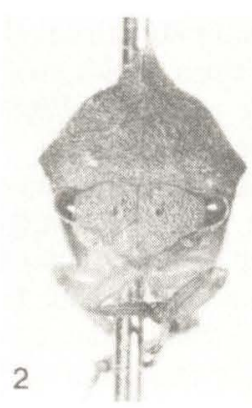
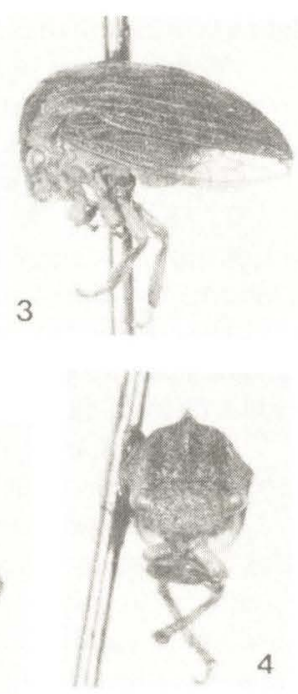

6
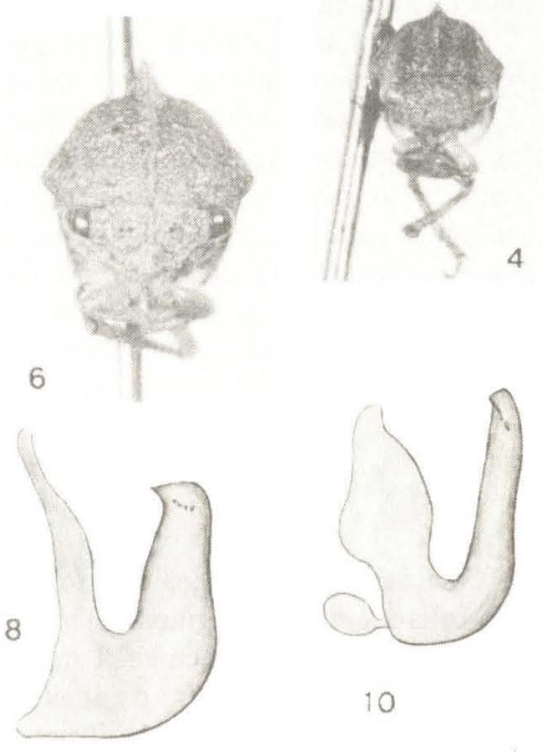

10

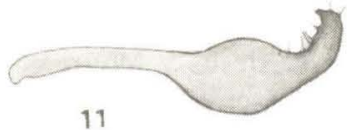

FIGS. 1-11: Ramedia juncta sp. n. - Holótipo (1, 2, 8 e 9); Ramedia costata sp. n. - Holótipo $(3,4,10$ e 11); Ramedia pauperata sp. n. - Holótipo $(5,6) ; 7$, tegmina. 